\title{
IDENTIFIKASI AUTOKORELASI SPASIAL PADA JUMLAHPENGANGGURAN DI JAWA TENGAH MENGGUNAKAN INDEKS MORAN
}

\author{
Triastuti Wuryandari ${ }^{1}$, Abdul Hoyyi ${ }^{2}$ \\ Dewi Setya Kusumawardani ${ }^{3}$, Dwi Rahmawati ${ }^{4}$ \\ ${ }^{1,2}$ Dosen Jurusan Statistika FMIPA UNDIP \\ ${ }^{3,4}$ Alumni Jurusan Statistika FMIPA UNDIP
}

\begin{abstract}
Unemployment is caused by the work force or job seekers are not proportional with the number of existing jobs. Unemployment is often a problem in the interconnected economy due to unemployment, productivity and income will be reduced. The number of unemployed in an are a expected to be affected by unemployment in the surrounding area. This is made possible because of the proximity factor or adjacency between regions, it is estimated that there are linkages to the regional unemployment rate. To determine the relationship between regional linkages used Moran's Index method. The number of unemployed in Central Java, obtained Moran's Index value $=0.0614$. Moran's Index values in the range $0<\mathrm{I} \leq 1$ indicating the presence of spatial autocorrelation is positive but small correlation can be said because of near zero, orit can be concluded that the similarity between the district does not have a value or indicate that unemployment among districts in Central Java has a small correlation.
\end{abstract}

Keywords: Unemployment, Moran's Index, Central Java, Autocorrelation, Spatial

\section{Pendahuluan}

Pengangguran adalah istilah untuk orang yang tidak bekerja sama sekali, sedang mencari kerja, bekerja kurang dari dua hari selama seminggu, atau seseorang yang sedang berusaha mendapatkan pekerjaan yang layak. Tingkat pengangguran dapat dihitung dengan cara membandingkan jumlah pengangguran dengan jumlah angkatan kerja yang dinyatakan dalam persen. Berdasarkan SAKERNAS (2011), jumlah angkatan kerja sebanyak 17.184.932 orang. Jumlah yang terserap bekerja sebanyak 16.142.436 orang (93,93 persen) dan yang tidak terserap sebanyak 1.042.496 orang (6,07 persen). Sektor yang paling banyak menyerap tenaga kerja adalah sektor pertanian, yakni sebanyak 5.819.439 orang atau 36,05 persen, kemudian dilanjutkan dengan sektor perdagangan yang menyerap 3.376.291 orang atau 20,92 persen dan sektor industri yang menampung 2.941 .036 orang atau 18,22 persen dari orang yang bekerja. Dari kelompok usia kerja ada sebanyak 17.184.932 orang tergolong dalam angkatan kerja. Persentase angkatan kerja terhadap penduduk usia kerja adalah 71,94 persen yang selanjutnya biasa disebut sebagai Tingkat Partisipasi Angkatan Kerja (TPAK). Penduduk yang tergolong angkatan kerja adalah kelompok orang yang bekerja maupun yang sedang mencari pekerjaan, mempersiapkan usaha, merasa tidak mungkin mendapatkan pekerjaan dan sudah diterima kerja tapi belum mulai bekerja. Penduduk bekerja pada Februari 2011 sebanyak 16.142.436 orang (93,93 persen) dan pengangguran sebanyak 1.042.496 orang atau 6,07 persen. Persentase ini umum dikenal sebagai Tingkat Pengangguran Terbuka (TPT). Sisa dari penduduk usia kerja sebanyak 6.703 .985 orang (sekitar 29,06 persen) tergolong sebagai bukan angkatan kerja. 
Jumlah pengangguran di suatu daerah diperkirakan dipengaruhi oleh jumlah pengangguran di daerah sekitarnya. Hal ini mungkin terjadi karena adanya faktor kedekatan atau ketetanggaan antar daerah. Oleh karena itu, diperkirakan terjadi adanya keterkaitan daerah terhadap jumlah pengangguran.

\section{Tinjauan Pustaka}

\subsection{Pengertian Statistika Spasial}

Statistika spasial adalah metode statistika yang digunakan untuk menganalisis data spasial. Data spasial adalah data yang memuat informasi "lokasi", jadi tidak hanya "apa" yang diukur tetapi menunjukkan lokasi dimana data itu berada ${ }^{[2]}$. Data-data spasial dapat berupa informasi mengenai lokasi geografi seperti letak garis lintang dan garis bujur dari masing-masing wilayah dan perbatasan antar daerah. Secara sederhana data spasial dinyatakan sebagai informasi alamat. Dalam bentuk yang lain, data spasial dinyatakan dalam bentuk grid koordinat seperti dalam sajian peta ataupun dalam bentuk pixel seperti dalam bentuk citra satelit ${ }^{[4]}$. Dengan demikian pendekatan analisis statistika spasial biasa disajikan dalam bentuk peta tematik.

Hukum pertama tentang geografi dikemukakan oleh $\mathrm{W}$ Tobler. Tobler dalam Anselin $^{[1]}$ mengemukakan bahwa, semua hal saling berkaitan satu dengan yang lainnya, tetapi sesuatu yang dekat akan lebih berkaitan dari pada hal yang berjauhan. Hukum inilah yang menjadi pilar mengenai kajian sains regional. Dapat disimpulkan bahwa efek spasial merupakan hal yang wajar terjadi antara satu daerah dengan daerah yang lainnya.

\subsection{Analisis Data Spasial}

Data spasial adalah data yang memuat adanya informasi lokasi atau geografis dari suatu wilayah. Menurut De Mers dalam Budiyanto ${ }^{[4]}$, analisis spasial mengarah pada banyak macam operasi dan konsep termasuk perhitungan sederhana, klasifikasi, penataan, tumpang-susun geometris, dan pemodelan kartografis. Secara umum analisis spasial membutuhkan suatu data data yang berdasarkan lokasi dan memuat karakteristik dari lokasi tersebut. Analisis spasial terdiri dari tiga kelompok yaitu visualisasi, eksplorasi, dan pemodelan. Visualisasi adalah menginformasikan hasil analisis spasial. Eksplorasi adalah mengolah data spasial dengan metode statistika. Sedangkan pemodelan adalah menunjukkan adanya konsep hubungan sebab akibat dengan menggunakan metode dari sumber data spasial dan data non spasial untuk memprediksi adanya pola spasial ${ }^{[6]}$. Lokasi pada data spasial harus diukur agar dapat mengetahui adanya efek spasial yang terjadi. Menurut Kosfeld ${ }^{[5]}$, informasi lokasi dapat diketahui dari dua sumber yaitu:

1. Hubungan ketetanggaan (neighborhood)

Hubungan ketetanggaan mencerminkan lokasi relatif dari satu unit spasial atau lokasi ke lokasi yang lain dalam ruang tertentu. Hubungan ketetanggaan dari unit-unit spasial biasanya dibentuk berdasarkan peta. Ketetanggaan dari unit-unit spasial ini diharapkan dapat mencerminkan derajat ketergantungan spasial yang tinggi jika dibandingkan dengan unit spasial yang letaknya terpisah jauh.

2. Jarak (distance)

Lokasi yang terletak dalam suatu ruang tertentu dengan adanya garis lintang dan garis bujur menjadi sebuah sumber informasi. Informasi inilah yang digunakan untuk menghitung jarak antar titik yang terdapat dalam ruang. Diharapkan kekuatan ketergantungan spasial akan menurun sesuai dengan jarak yang ada. 
Hal yang sangat penting dalam analisis spasial adalah adanya pembobot atau sering disebut sebagai matriks pembobot spasial. Matriks pembobot spasial digunakan untuk menentukan bobot antar lokasi yang diamati berdasarkan hubungan ketetanggaan antar lokasi. Menurut Kosfeld ${ }^{[5]}$, pada grid umum ketetanggaan dapat didefinisikan dalam beberapa cara, yaitu:

a. Rook contiguity

Daerah pengamatannya ditentukan berdasarkan sisi-sisi yang saling bersinggungan dan sudut tidak diperhitungkan. Ilustrasi rook contiguity dilihat pada Gambar 1, dimana unit B1, B2, B3, dan B4 merupakan tetangga dari unit A

\begin{tabular}{|l|l|l|l|l|}
\hline & & & & \\
\hline & & Unit B2 & & \\
\hline & Unit B1 & Unit A & Unit B3 & \\
\hline & & Unit B4 & & \\
\hline & & & & \\
\hline
\end{tabular}

Gambar 1. Rook Contiguity

b. Bishop contiguity

Daerah pengamatannya ditentukan berdasarkan sudut-sudut yang saling bersinggungan dan sisi tidak diperhitungkan. Ilustrasi untuk bishop contiguity dilihat pada Gambar 2, dimana unit C1, C2, C3, dan C4 merupakan tetangga dari unit A

\begin{tabular}{|l|l|l|l|l|}
\hline & & & & \\
\hline & Unit C1 & & Unit C2 & \\
\hline & & Unit A & & \\
\hline & Unit C4 & & Unit C3 & \\
\hline & & & & \\
\hline
\end{tabular}

Gambar 2. Bishop Contiguity

c. Queen contiguity

Daerah pengamatannya ditentukan berdasarkan sisi-sisi yang saling bersinggungan dan sudut juga diperhitungkan. Ilustrasi untuk queen contiguity dapat dilihat pada Gambar 3, dimana unit B1, B2, B3, dan B4 serta C1, C2, C3, dan C4 merupakan tetangga dari unit $\mathrm{A}$

\begin{tabular}{|l|c|c|c|l|}
\hline & & & & \\
\hline & Unit C1 & Unit B2 & Unit C2 & \\
\hline & Unit B1 & Unit A & Unit B3 & \\
\hline & Unit C4 & Unit B4 & Unit C3 & \\
\hline & & & & \\
\hline
\end{tabular}

Gambar 3. Queen Contiguity 
Pada umumnya ketetanggaan antar lokasi didasarkan pada sisi-sisi utama bukan sudutnya. Menurut Kosfeld ${ }^{[5]}$, matriks pembobot spasial W dapat diperoleh dari dua cara yaitu matriks pembobot terstandarisasi (standardize contiguity matrix $\boldsymbol{W}$ ) dan matriks pembobot tak terstandarisasi (unstandardize contiguity matrix $\boldsymbol{W}^{*}$ ). Matriks pembobot terstandarisasi (standardize contiguity matrix $\boldsymbol{W}$ ) merupakan matriks pembobot yang diperoleh dengan cara memberikan bobot yang sama rata terhadap tetangga lokasi terdekat dan yang lainnya nol, sedangkan matriks pembobot tak terstandarisasi (unstandardize contiguity matrix $\boldsymbol{W}^{*}$ ) merupakan matriks pembobot yang diperoleh dengan cara memberikan bobot satu bagi tetangga terdekat dan yang lainnya nol.

\subsection{Autokorelasi Spasial}

Autokorelasi spasial adalah taksiran dari korelasi antar nilai amatan yang berkaitan dengan lokasi spasial pada variabel yang sama. Autokorelasi spasial positif menunjukkan adanya kemiripan nilai dari lokasi-lokasi yang berdekatan dan cenderung berkelompok. Sedangkan autokorelasi spasial yang negatif menunjukkan bahwa lokasi-lokasi yang berdekatan mempunyai nilai yang berbeda dan cenderung menyebar.

Karekteristik dari autokorelasi spasial yang diungkapkan oleh Kosfeld ${ }^{[5]}$, yaitu:

1. Jika terdapat pola sistematis pada distribusi spasial dari variabel yang diamati, maka terdapat autokorelasi spasial.

2. Jika kedekatan atau ketetanggaan antar daerah lebih dekat, maka dapat dikatakan ada autokorelasi spasial positif.

3. Autokorelasi spasial negatif menggambarkan pola ketetanggaan yang tidak sistematis.

4. Pola acak dari data spasial menunjukkan tidak ada autokorelasi spasial.

Pengukuran autokorelasi spasial untuk data spasial dapat dihitung menggunakan metode Moran's Index (Indeks Moran), Geary's C, dan Tango's excess ${ }^{[6]}$. Pada penelitian ini metode analisis hanya dibatasi pada metode Moran's Index (Indeks Moran). Indeks Moran (Moran's I) merupakan metode yang paling banyak digunakan untuk menghitung autokorelasi spasial secara global. Metode ini dapat digunakan untuk mendeteksi permulaan dari keacakan spasial. Keacakan spasial ini dapat mengindikasikan adanya polapola yang mengelompok atau membentuk tren terhadap ruang ${ }^{[5]}$. Menurut Kosfeld ${ }^{[5]}$, perhitungan autokorelasi spasial dengan metode Indeks Moran dapat dilakukan dengan dua cara, yaitu:

1. Indeks Moran dengan matriks pembobot spasial tak terstandarisasi $\mathrm{W}^{*}$

$$
I=\frac{n \sum_{i=1}^{n} \sum_{j=1}^{n} w_{i j}^{*}\left(x_{j}-\bar{x}\right)\left(x_{j}-\bar{x}\right)}{S_{0} \sum_{i=1}^{n}\left(x_{i}-\bar{x}\right)}
$$

dengan $S_{0}=\sum_{i=1}^{n} \sum_{j=1}^{n} w_{i j}^{*}$

$w_{i j}^{*}$ : elemen pada pembobot tak terstandarisasi antara daerah $i$ dan $j$,

2. Indeks Moran dengan matriks pembobot spasial terstandarisasi $\mathrm{W}$

$$
I=\frac{n \sum_{i=1}^{n} \sum_{j=1}^{n} w_{i j}\left(x_{j}-\bar{x}\right)\left(x_{j}-\bar{x}\right)}{\sum_{i=1}^{n}\left(x_{i}-\bar{x}\right)^{2}}
$$




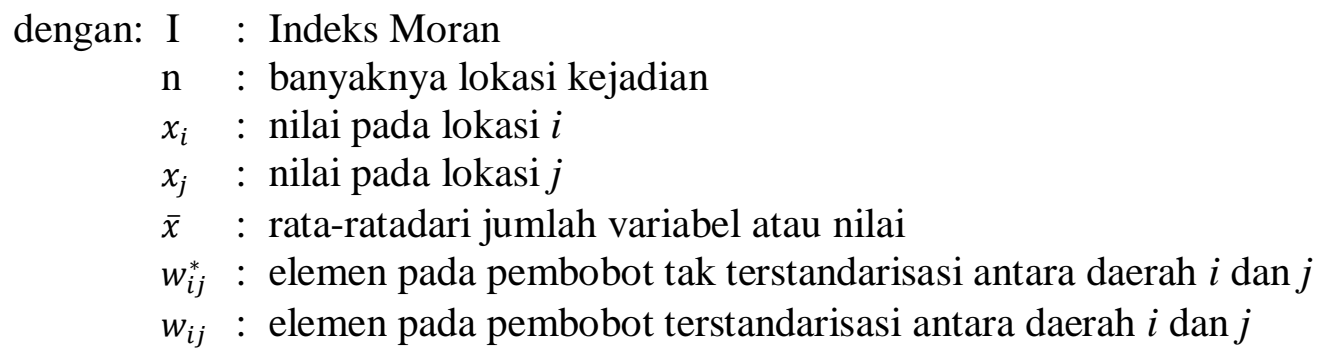

Rentang nilai dari Indeks Moran dalam kasus matriks pembobot spasial terstandarisasi adalah $-1 \leq \mathrm{I} \leq 1$.Nilai $-1 \leq \mathrm{I}<0$ menunjukkan adanya autokorelasi spasial negatif, sedangkan nilai $0<\mathrm{I} \leq 1$ menunjukkan adanya autokorelasi spasial positif, nilai Indeks Moran bernilai nol mengindikasikan tidak berkelompok. Nilai Indeks Moran tidak menjamin ketepatan pengukuran jika matriks pembobot yang digunakan adalah pembobot tak terstandarisasi.Untuk mengidentifikasi adanya autokorelasi spasial atau tidak, dilakukan uji signifikansi Indeks Moran.

Uji hipotesis untuk Indeks Moran adalahsebagai berikut:

i. Hipotesis $\mathrm{H}_{0}$ : Tidak terdapat autokorelasi spasial

$\mathrm{H}_{1}$ : Terdapat autokorelasi spasial

ii. Tingkat signifikansi: $\alpha$

$$
\begin{aligned}
& \text { iii. Statistik uji: } \quad Z(I)=\frac{I-E(I)}{\sqrt{\operatorname{Var}(I)}} \approx N(0,1) \\
& \text { dengan } \mathrm{E}(\mathrm{I})=-\frac{1}{\mathrm{n}-1} \quad \operatorname{Var}(I)=\frac{n^{2} \cdot S_{1}-n \cdot S_{2}+3 \cdot S_{0}^{2}}{\left(n^{2}-1\right) S_{0}^{2}}-[E(I)]^{2} \\
& \mathrm{~S}_{0}=\sum_{\mathrm{i}=1}^{\mathrm{n}} \sum_{\mathrm{j}=1}^{\mathrm{n}} \mathrm{w}_{\mathrm{ij}} \quad \mathrm{S}_{1}=\frac{1}{2} \sum_{\mathrm{i}=1}^{\mathrm{n}} \sum_{\mathrm{j}=1}^{\mathrm{n}}\left(\mathrm{w}_{\mathrm{ij}}+\mathrm{w}_{\mathrm{ji}}\right)^{2} \quad \mathrm{~S}_{2}=\sum_{\mathrm{i}=1}^{\mathrm{n}}\left(\sum_{\mathrm{j}=1}^{\mathrm{n}} \mathrm{w}_{\mathrm{ij}}+\sum_{\mathrm{j}=1}^{\mathrm{n}} \mathrm{w}_{\mathrm{ji}}\right)^{2}
\end{aligned}
$$

Kriteria uji:

Tolak $\mathrm{H}_{0}$ pada taraf signifikasi $\alpha$ jika $Z(I)>Z_{1-\alpha}$ dengan $Z_{1-\alpha}$ adalah (1- $\left.\alpha\right)$ kuantil dari distribusi normal standar

\subsection{Moran Scatterplot}

Moran Scatterplot adalah alat yang digunakan untuk melihat hubungan antara nilai pengamatan yang terstandarisasi dengan nilai rata-rata tetangga yang sudah terstandarisasi. Jika digabungkan dengan garis regresi maka hal ini dapat digunakan untuk mengetahui derajat kecocokan dan mengidentifikasi adanya outlier. Moran Scatterplot dapat digunakan untuk mengidentifikasi keseimbangan atau pengaruh spasial ${ }^{[1]}$. Tipe-tipe hubungan spasial dapat dilihat dari Gambar 4.

\begin{tabular}{c|c} 
Kuadran I atau HH (High-High) & Kuadran IV atau HL (High-Low) \\
\hline Kuadran II atau LH (Low-High) & Kuadran III atau LL (Low-Low)
\end{tabular}

Gambar 4. Moran Scatterplot 
Menurut Zhukov (2010) ${ }^{[7]}$, kuadran-kuadran dalam Moran Scatterplot adalah sebagai berikut:

1. Pada kuadran I, HH (High-High) menunjukkan bahwa daerah yang mempunyai nilai pengamatan tinggi dikelilingi oleh daerah yang mempunyai nilai pengamatan tinggi.

2. Pada kuadran II, LH (Low-High) menunjukkan bahwa daerah yang mempunyai nilai pengamatan rendah dikelilingi oleh daerah yang mempunyai nilai pengamatan tinggi.

3. Pada kuadran III, LL (Low-low) menunjukkan bahwa daerah yang mempunyai nilai pengamatan rendah dikelilingi oleh daerah yang mempunyai nilai pengamatan rendah.

4. Pada kuadran IV, HL (High-Low) menunjukkan bahwa daerah yang mempunyai nilai pengamatan tinggi dikelilingi oleh daerah yang mempunyai nilai pengamatan rendah.

\section{Metode Penelitian}

Data yang digunakan dalam penelitian ini merupakan data sekunder yang diperoleh dari BPS tentang data jumlah pengangguran di Jawa Tengah pada tahun 2011 berdasarkan kabupaten/kota. Berikut adalah data jumlah pengangguran di Jawa Tengah tahun 2011

Tabel 1. Jumlah Pengangguran di Kabupaten/Kota Jawa Tengah

\begin{tabular}{|c|l|c|c|l|c|}
\hline No & Kab/Kodya & Jumlah & No & Kab/ Kodya & Jumlah \\
\hline 1 & Cilacap & 57.222 & 19 & Kudus & 25.522 \\
\hline 2 & Banyumas & 37.928 & 20 & Jepara & 24.085 \\
\hline 3 & Purbalingga & 24.218 & 21 & Demak & 45.496 \\
\hline 4 & Banjarnegara & 19.019 & 22 & Semarang & 26.344 \\
\hline 5 & Kebumen & 23.134 & 23 & Temanggung & 13.975 \\
\hline 6 & Purworejo & 11.701 & 24 & Kendal & 30.819 \\
\hline 7 & Wonosobo & 22.379 & 25 & Batang & 22.368 \\
\hline 8 & Magelang & 29.252 & 26 & Pekalongan & 21.684 \\
\hline 9 & Boyolali & 23.550 & 27 & Pemalang & 29.539 \\
\hline 10 & Klaten & 22.778 & 28 & Tegal & 38.645 \\
\hline 11 & Sukoharjo & 25.590 & 29 & Brebes & 65.848 \\
\hline 12 & Wonogiri & 18.980 & 30 & Kota Magelang & 5.501 \\
\hline 13 & Karanganyar & 25.642 & 31 & Kota Surakarta & 16.523 \\
\hline 14 & Sragen & 29.673 & 32 & Kota Salatiga & 6.000 \\
\hline 15 & Grobogan & 31.526 & 33 & Kota Semarang & 46.801 \\
\hline 16 & Blora & 22.657 & 34 & Kota Pekalongan & 10.596 \\
\hline 17 & Rembang & 19.511 & 35 & Kota Tegal & 9.468 \\
\hline 18 & Pati & 78.177 & & Jumlah & $\mathbf{9 6 2 . 1 5 1}$ \\
\hline
\end{tabular}

\section{Hasil Dan Pembahasan}

\subsection{Matriks Pembobot Spasial}

Dalam analisis spasial untuk menentukan adanya autokorelasi spasial, komponen utama yang diperlukan adalah peta lokasi. Peta digunakan untuk menentukan hubungan kedekatan antar kabupaten di Jawa Tengah. Dengan demikian akan lebih mudah untuk memberi pembobot pada masing-masing lokasi atau kabupaten. Dari peta provinsi Jawa Tengah diketahui bahwa terdapat 35 kabupaten sehingga matriks pembobot spasial akan berukuran $35 x 35$. Metode pembobotan matriks yang digunakan adalah rook contiguity dan 
cara memperoleh matriks pembobot spasial berdasarkan standardize contiguity matrix $\boldsymbol{W}$ (matriks pembobot terstandarisasi). Standardize contiguity matrix $\boldsymbol{W}$ (matriks pembobot terstandarisasi) diperoleh dengan cara memberikan nilai atau bobot yang sama rata terhadap tetangga lokasi terdekat dan lokasi yang lainnya diberi bobot nol. Berdasarkan matriks pembobot spasial, dapat diketahui jumlah tetangga lokasi yang dimiliki oleh masing-masing kabupaten. Grafik jumlah ketetanggaan tiap kabupaten adalah sebagai berikut:

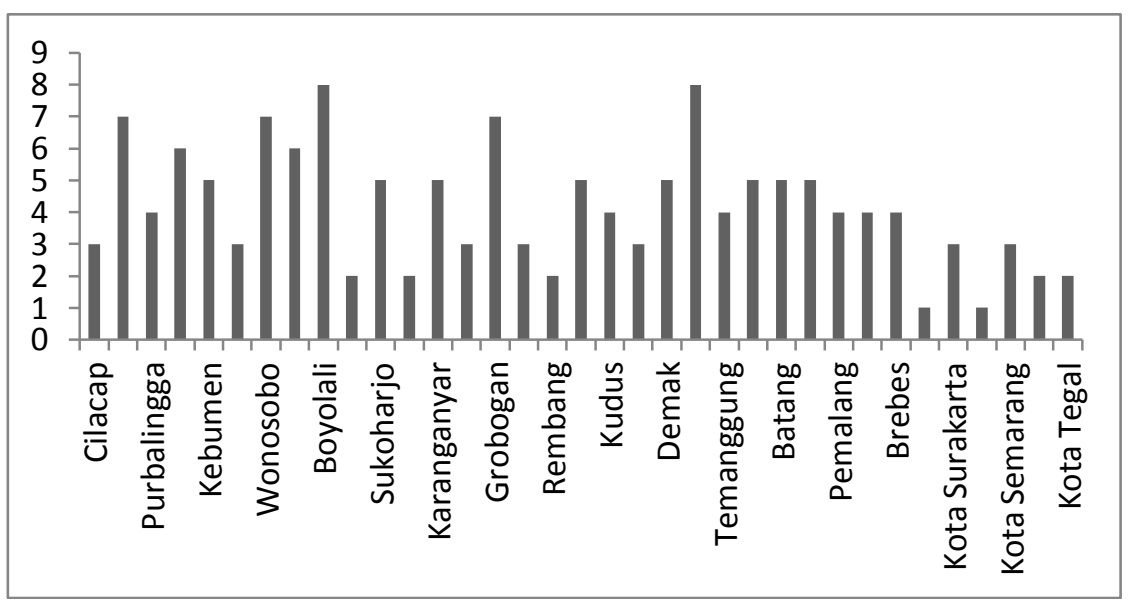

Gambar 5. Jumlah Ketetanggaan Tiap Kabupaten

Grafik jumlah ketetanggan merupakan grafik yang menerangkan jumlah dari lokasi kabupaten yang berbatasan langsung sesuai dengan ketentuan rook contiguity dengan kabupaten yang diamati. Berdasarkan gambar 5, dapat diketahui bahwa kabupaten yang mempunyai batas lokasi (tetangga) terbanyak adalah Kabupaten Boyolali dan Kabupaten Semarang yaitu sebanyak 8 tetangga. Selanjutnya kabupaten yang mempunyai batas lokasi (tetangga) paling sedikit adalah Kota Magelang dan Kota Salatiga memiliki jumlah 1 tetangga.

\subsection{Indeks Moran}

Indeks Moran (Moran's Index) adalah salah satu teknik analisis spasial yang dapat digunakan untuk menentukan adanya autokorelasi spasial antar lokasi pengamatan. Perhitungan Indeks Moran adalah sebagai berikut:

$$
I=\frac{\sum_{i=1}^{n} \sum_{j=1}^{n} w_{i j}\left(x_{i}-\bar{x}\right)\left(x_{j}-\bar{x}\right)}{\sum_{i=1}^{n}\left(x_{i}-\bar{x}\right)^{2}}=\frac{516450909,7}{8410695275}=0,0614
$$

Pada uji signifikansi digunakan pendekatan normal untuk mengetahui apakah terdapat autokorelasi spasial atau tidak. Uji hipotesisnya adalah sebagai berikut:

i. Hipotesis $\mathrm{H}_{0}$ : Tidak terdapat autokorelasi spasial

$$
\mathrm{H}_{1} \text { : Terdapat autokorelasi spasial }
$$

ii. Tingkat signifikansi $\alpha=5 \%$

iii. Statistik uji

$$
E(I)=-\frac{1}{n-1}=-\frac{1}{35-1}=-\frac{1}{34}=-0,02941
$$




$$
\begin{aligned}
& S_{0}=\sum_{i=1}^{n} \sum_{j=1}^{n} w_{i j}=\left(\frac{1}{3}+\frac{1}{3}+\ldots+\frac{1}{2}\right)=35 \\
& S_{1}=\frac{1}{2} \sum_{i=1}^{n} \sum_{j=1}^{n}\left(w_{i j}+w_{j i}\right)^{2}=\frac{1}{2}\left[\left(\frac{1}{3}+\frac{1}{7}\right)^{2}+\left(\frac{1}{7}+\frac{1}{3}\right)^{2}+\ldots+\left(\frac{1}{2}+\frac{1}{4}\right)\right]=18,9401 \\
& S_{2}=\sum_{i=1}^{n}\left(\sum_{j=1}^{n} w_{i j}+\sum_{j=1}^{n} w_{j i}\right)^{2}=\left[\left(1+\frac{25}{28}\right)^{2}+\left(1+\frac{3}{2}\right)^{2}+\ldots+\left(1+\frac{1}{2}\right)^{2}\right]=150,97393 \\
& \operatorname{Var}(I)=\frac{n^{2} S_{1}-n S_{1}+3 S_{0}^{2}}{\left(n^{2}-1\right) S_{0}^{2}}-[E(I)]^{2} \\
& \operatorname{Var}(I)=\frac{35^{2}(18,9401)-34(150,97393)+3\left(35^{2}\right)}{\left(35^{2}-1\right)\left(35^{2}\right)}-[0,02941]^{2}=0,01354 \\
& Z(I)=\frac{I-E(I)}{\sqrt{\operatorname{Var}(I)}}=\frac{0,0614-(-0,02941)}{\sqrt{0,01354}}=0,78059
\end{aligned}
$$

iv. Kriteria uji:

Tolak $\mathrm{H}_{0}$ pada taraf signifikasi $\alpha$ jika $Z(I)>Z_{1-\alpha}$, dengan $\mathrm{Z}_{1-\alpha}=\mathrm{Z}_{0,95}=1,645$

v. Kesimpulan:

Dari hasil perhitungan dapat diketahui bahwa nilai $\mathrm{Z}(I)=0,78059<\mathrm{Z}_{0,95}=1,645$.

Sehingga $\mathrm{H}_{0}$ diterima atau kesimpulan bahwa tidak terdapat autokorelasi spasial.

Dari pengujian Indeks Moran diperoleh kesimpulan bahwa pada taraf signifikansi 5\% dinyatakan tidak terdapat autokorelasi spasial tehadap jumlah pengangguran di Jawa Tengah pada tahun 2011. Nilai Indeks Moran sebesar 0,0614 berada pada rentang $0<I \leq 1$ dan menunjukkan adanya autokorelasi spasial positif namun korelasinya dapat dikatakan lemah karena mendekati nol. Berarti disimpulkan bahwa antar kabupaten satu dengan yang lainnya tidak memiliki kemiripan nilai atau mengindikasikan bahwa data tidak berkelompok.

\subsection{Moran Scatterplot}

Moran scatterplot disajikan pada Gambar 6 berikut, titik-titik menyebar diantara kuadran I, II, III, dan IV. Analisis Moran scatterplot dilakukan dengan software GeoDa dan diperoleh hasil sebagai berikut:

1. Pada kuadran I, HH (High-High) menunjukkan bahwa daerah yang mempunyai nilai pengamatan tinggi dikelilingi oleh daerah yang mempunyai nilai pengamatan tinggi. Kabupaten yang berada dalam kuadran I adalah Kabupaten Semarang, Purbalingga, Temanggung, Blora, Kudus, Jepara, Rembang, Kebumen, Kota Magelang, dan Kota Tegal.

2. Pada kuadran II, LH (Low-High) menunjukkan bahwa daerah yang mempunyai nilai pengamatan rendah dikelilingi oleh daerah yang mempunyai nilai pengamatan tinggi. Kabupaten yang berada dalam kuadran II adalah Kabupaten Boyolali, Klaten, Banjarnegara, 
3. Wonogiri, Purworejo, Karanganyar, Sukoharjo, Wonosobo, Batang, Pekalongan, Kota Surakarta, Kota Salatiga, dan Kota Pekalongan.

4. Pada kuadran III, LL (Low-low) menunjukkan bahwa daerah yang mempunyai nilai pengamatan rendah dikelilingi oleh daerah yang mempunyai nilai pengamatan rendah. Kabupaten yang berada dalam kuadran III adalah Kabupaten Magelang, Pati, Kendal, dan Sragen.

5. Pada kuadran IV, HL (High-Low) menunjukkan bahwa daerah yang mempunyai nilai pengamatan tinggi dikelilingi oleh daerah yang mempunyai nilai pengamatan rendah. Kabupaten yang berada dalam kuadran IV adalah Kabupaten Brebes, Cilacap, Demak, Tegal, Banyumas, Grobogan, Pemalang, dan Kota Semarang.

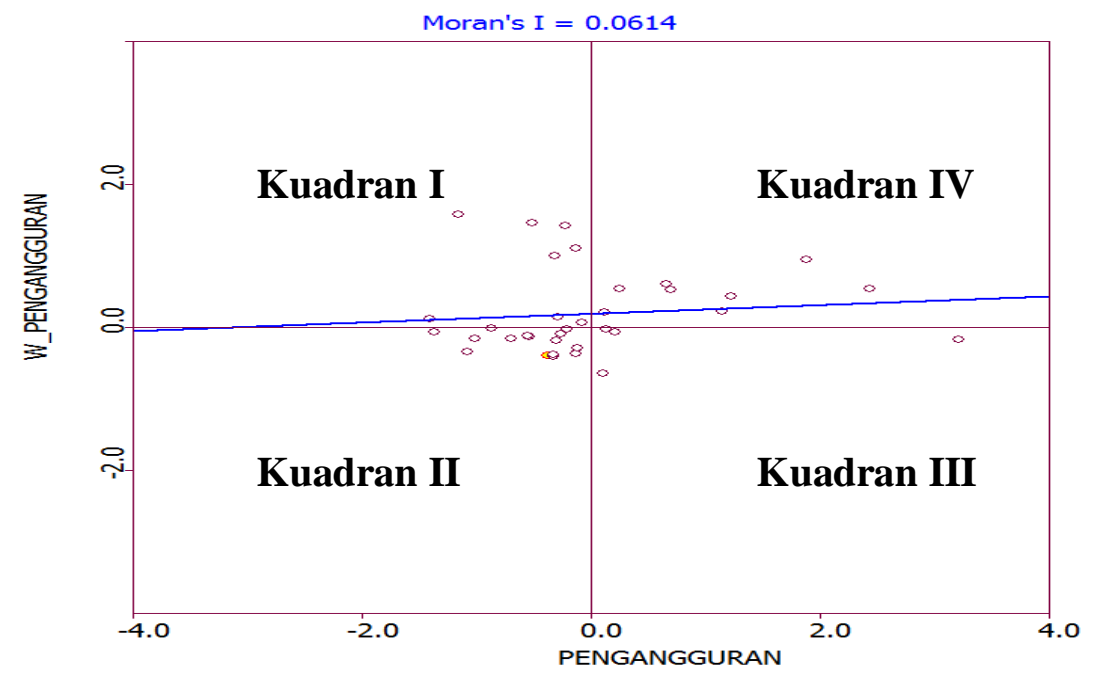

Gambar 6. Moran Scatterplot dari Jumlah Pengangguran

Peta penyebaran pengangguran di Jawa Tengah tahun 2011 berdasarkan Moran Scatterplot adalah sebagai berikut:

\section{PETA PENYEBARAN PENGANGGURAN \\ DI JAWA TENGAH TAHUN 2011}

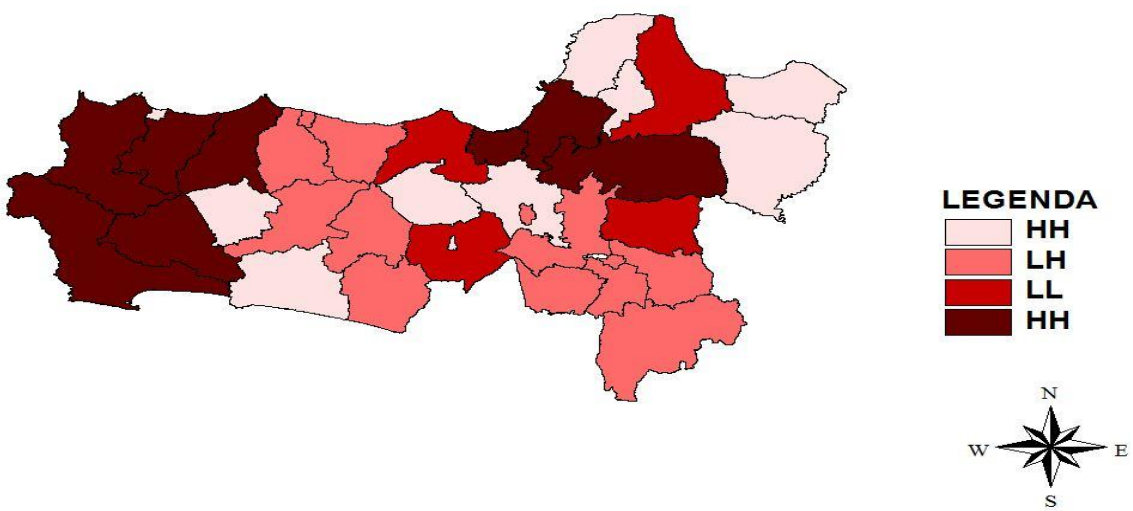

Gambar 7. Peta Penyebaran Penganggurandi Jawa Tengah Tahun 2011 


\section{Kesimpulan} berikut:

Berdasarkan hasil analsisis dan pembahasan, dapat diperoleh kesimpulan sebagai

1. Berdasarkan perhitungan, nilai Indeks Moran $I=0,0614$. Nilai Indeks Moran ini berada pada rentang $0<I \leq 1$ sehingga menunjukkan adanya autokorelasi spasial positif namun korelasinya dapat dikatakan lemah karena mendekati nol, sehingga menyebabkan tidak adanya autokorelasi spasial pada pengujian signifikansi indeks Moran.

2. Berdasarkan pengujian signifikansi Indeks Moran dengan taraf signifikansi 5\% dapat diperoleh kesimpulan bahwa antar kabupaten satu dengan yang lainnya tidak memiliki kemiripan nilai atau mengindikasikan bahwa pengangguran antar Kabupaten di Jawa Tengah tidak saling berkorelasi.

\section{DAFTAR PUSTAKA}

1. Anselin, L., Exploratory Spatial Data Analysis and Geographic Information Systems, National Center for Geographic Information and Analysis of California Santa Barbara: CA93106,1993.

2. Banerjee,S., Hierarchical Modeling and Analysis for Spatial Data, Chapman and Hall/CRC, Boca Raton, 2004.

3. Bollerslev, T., Generalized Autoregressive Conditional Heteroskedasticity, Journal of Econometrics, 1986, Vol. 31: 307-327.

4. Budiyanto, E., Sistem Informasi Geografis dengan ArcView GIS, Penerbit Andi, Yogyakarta,2010.

5. Kosfeld, R., Spatial Econometric, 2006, URL: http://www.scribd.com

6. Pfeiffer, D et al., Spatial Analysis in Epidemiologi, Oxford University Press., New York, 2008.

7. Zhukof, Y., Spatial Autocorrelation, IQQS, Harvard University, Amerika, 2010. 